\title{
AN ADVANCED SEISMIC ANALYSIS OF NPP POWERFUL TURBOGENERATOR ON ISOLATION PEDESTAL
}

\author{
Victor V. Kostarev \\ CKTI-Vibroseism Co. Ltd., St. Petersburg, \\ Russian Federation \\ Phone: +78123278599 , \\ Fax: +78123278599 \\ E-mail: vvk@cvs.spb.su
}

\author{
Andrei V. Petrenko \\ CKTI-Vibroseism Co. Ltd., St. Petersburg, \\ Russian Federation \\ Phone: +7 8123278599 , \\ Fax: +78123278599 \\ E-mail: andrey@cvs.spb.su
}

\author{
Peter S. Vasilyev \\ CKTI-Vibroseism Co. Ltd., St. Petersburg, Russian Federation \\ Phone: +7812 3278599, Fax: +7 8123278599 \\ E-mail: peter@cvs.spb.su
}

\begin{abstract}
Paper deals with the detailed seismic analysis of powerful high-speed Russian turbine of Nuclear Power Plant. Dozens of patterns of such turbine work reliably since 70's worldwide. Until last decade only simplified structural analyses were available due to a complicated overall structure and internals of such turbines. The current analysis considers detail geometry of the turbine itself and vibration and seismic isolation system within turbine's pedestal and full range of operational, accident and seismic loads like a high pressure, outside loads induced by pipelines and so on.

To solve the problem of the turbine seismic qualification the following steps have been done. On the first step detailed finite element models of turbine's high and low pressure parts and rotor system with bearings were created. Using such models corresponding simplified models were developed to be included into the coupled model of the system: "Building - Vibroisolation Pedestal - Turbine" (BVT). The second step was the analysis of that coupled system. Soil-structure interaction was considered using actual soil conditions. Three components of time history acceleration were used to define seismic excitation. As the result of BVT system analysis a full picture of time history displacements and loads were determined. At the same time a problem of rotor gaps was solved. On the final step determined loads were applied to the detailed model of turbine for seismic qualification of the whole structure.
\end{abstract}

Keywords: Turbogenerator, Vibroisolation Pedestal, NPP, Seismic Analysis

\section{INTRODUCTION}

Generally turbine is a part of the secondary side of two loops light water reactor PWR or VVER Nuclear Power Plants. Under normal operation mode it does not contain any radioactive flow or materials and usually does not perform any safety function. Thus turbine is not included in the NPP safe shutdown equipment list. As a unique and extremely expensive NPP component turbines should meet conventional industrial codes' requirements for seismic protection to mitigate potential human and component losses under design earthquake. 
However in some cases in accordance with initial design or as a result of safety upgrading measures, as it for example happened at NPP Paks, Hungary and on some other plants, turbine is included in the auxiliary safety heat removal system providing additional source for reactor's safe shutdown. In that case a turbine appropriates higher safety class and seismic category with necessity for in-depth seismic analysis on upgraded level of design earthquake.

In some IAEA member states turbines are also under consideration as a potential source of missile objects that could cause damage for safety related systems and components. These objects may appear after one or multiple brakes of low pressure side turbine's blades due to accident conditions or some external event impact.

Topical questions for NPP powerful turbine safety are also short-circuit of the turbo-generator rotor and turbine rotor runaway that could bring to the system essential dynamic excitation with current probability for rotor's guillotine break and missile objects origin. These modes of turbine failure considering its outstanding potential energy could initiate catastrophic consequences for turbine itself and for plant safety systems and NPP structures.

All discussed points require careful analysis of extremely complicated turbo-generator system with isolation spring/dampers pedestal from positions of modern finite-element structural analysis and safety requirements.

This paper deals with a seismic analysis of high power and high rotating speed turbine installed at Nuclear Power Plant (NPP) recently designed by Russia. A minimum intensity of seismic excitation $0.1 \mathrm{~g}$ should be used in design of NPPs buildings, structures and components according to Russians (Gosatomnadzor, 2002) and international (IAEA, 1992) codes.

At one hand, the turbine is one of the most important and complicated system for manufacturing, testing, maintenance and operation. It consists of a big number of internal elements connecting to each other. At the other hand, turbine has a huge mass, lies on a pedestal with length comparable to a building size. So it can influence on the whole building behavior during earthquake. That is the reason to analyze complete system "Building Vibroisolation Pedestal - Turbine" (BVT). In recent decade, only simplified structural analyses of the separate turbine parts were available due to the complicated overall structure and internals of this class of turbine.

The scope of present work includes seismic analysis of complete BVT system as well as the detailed analyses of the parts of the turbine itself.

For these reasons, first, a detailed spatial model of turbine hall building was developed. Most simplified models of turbine and vibroisolation were incorporated into it. Seismic analysis of such model considers three variations of soil and three components of seismic excitation on free soil surface. Approach of soil impedance was applied regarding (ASCE, 1998). As the result of analysis, design seismic excitation on the base slab was determined.

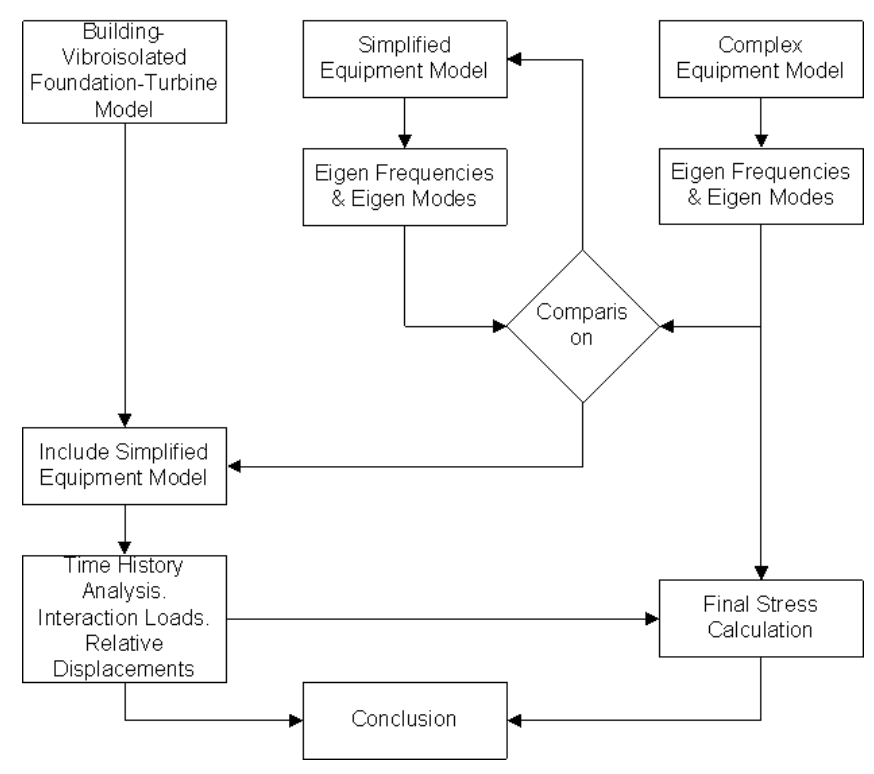

Fig. 1 Analysis Flowchart
Second, for the main turbine parts (high pressure part, low pressure part, condenser and rotor with bearings) detailed spatial models were developed. Using it, simplified models of these turbine parts were also created to be included into the model of BVT system.

Third, dynamic analysis of the coupled model BVT under design seismic excitation was done. As the result, a full picture of time history relative displacements and loads of turbine parts were correctly determined, as well as a solution to a problem of rotor gaps.

Finally, seismic analyses of turbine parts using detailed models were carried out under all operational and seismic loads determined in BVT's analysis. 


\section{DESIGN SEISMIC EXCITATION}

Seismic excitation was defined by three components of time history acceleration on free ground surface. The average soil conditions were calculated using average values of velocities of compressional and shear seismic waves (Бирбраер, 1998). Two additional variations of soil were included in the analysis to take into account uncertainties of soil properties (ASCE, 1998).

The detailed spatial model of turbine hall was developed (Fig. 2). The building may be functionally divided into the four parts: turbine section, power supply section, oil supply section and generator section. That is the reason the building constructively consists of cast reinforced concrete parts as well as concrete skeleton with metal frame roof.

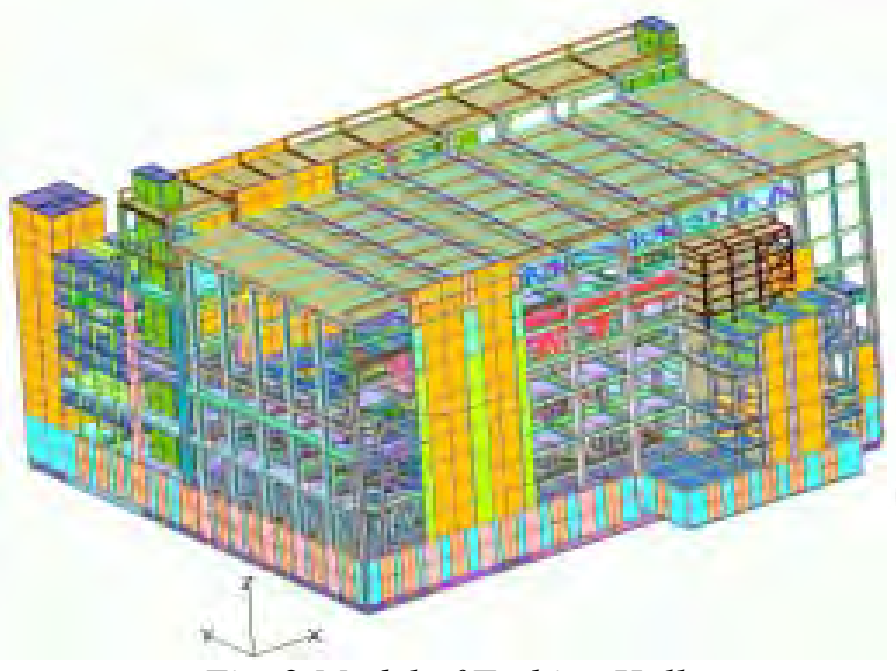

Fig. 2 Model of Turbine Hall

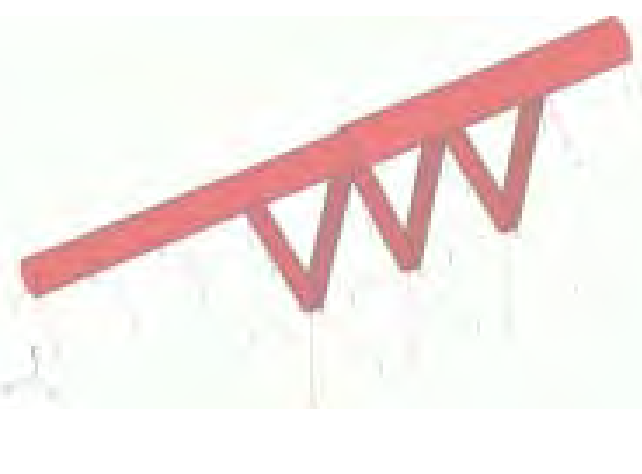

Fig. 3 Most Simplified Model of the Turbine and Vibroisolation System

At this stage of analysis the extremely simplified models of equipment were coupled to the model of building. It was done only for equipment with mass which is comparative to the building's mass (> 1\%)(ASCE, 1998): turbine with vibroisolation system, deaerator etc. (Fig. 3).

Direct linear time history analysis was carried out with consideration of three samples of soil to develop broaden envelope response spectra for the building base mat (Fig. 4). Three components of time history acceleration were synthesized to be compatible with these spectra (US NRC, 1989). This allowed to exclude consideration of variation of soil properties and leaded to one variant of further analysis.

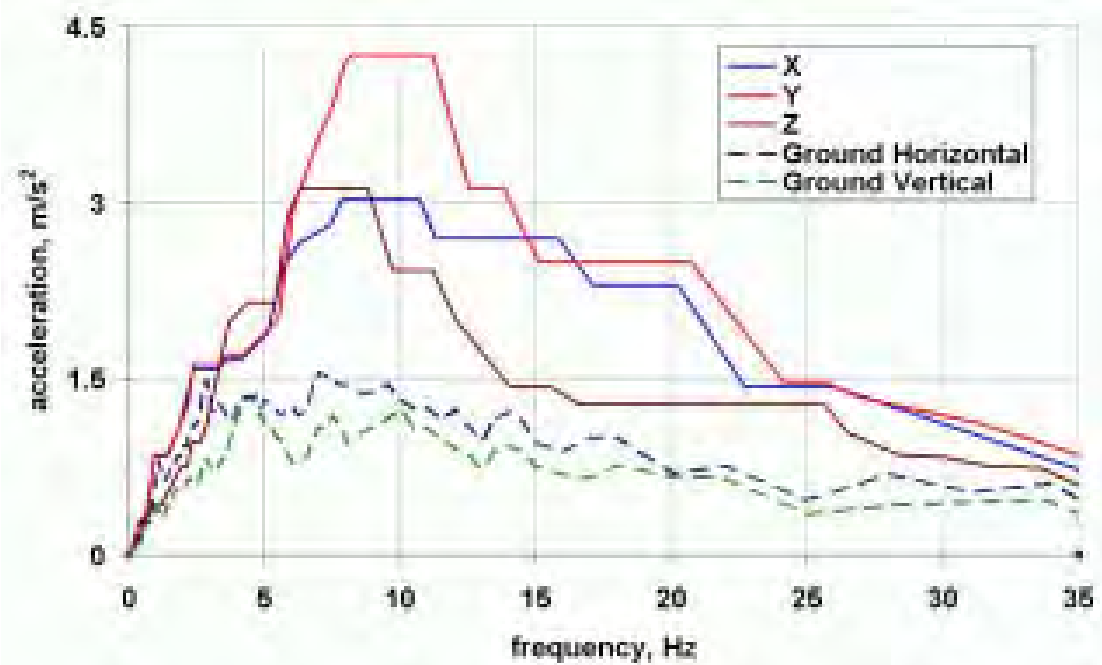

Fig. 4 Seismic Broaden Envelope Spectra for Building Base Mat (Damping 5\%) 


\section{DEVELOPMENT OF COMPATIBLE DETAILED AND SIMPLIFIED MODELS OF TURBINE'S PARTS AND VIBROISOLATION PEDESTAL}

The detailed spatial models were developed for all main turbine parts. At the same time the analysis of dynamic properties (inertia, eigenvalues and stiffness) of these models allowed to create corresponding simplified models to be included to the building model and correct their characteristics.

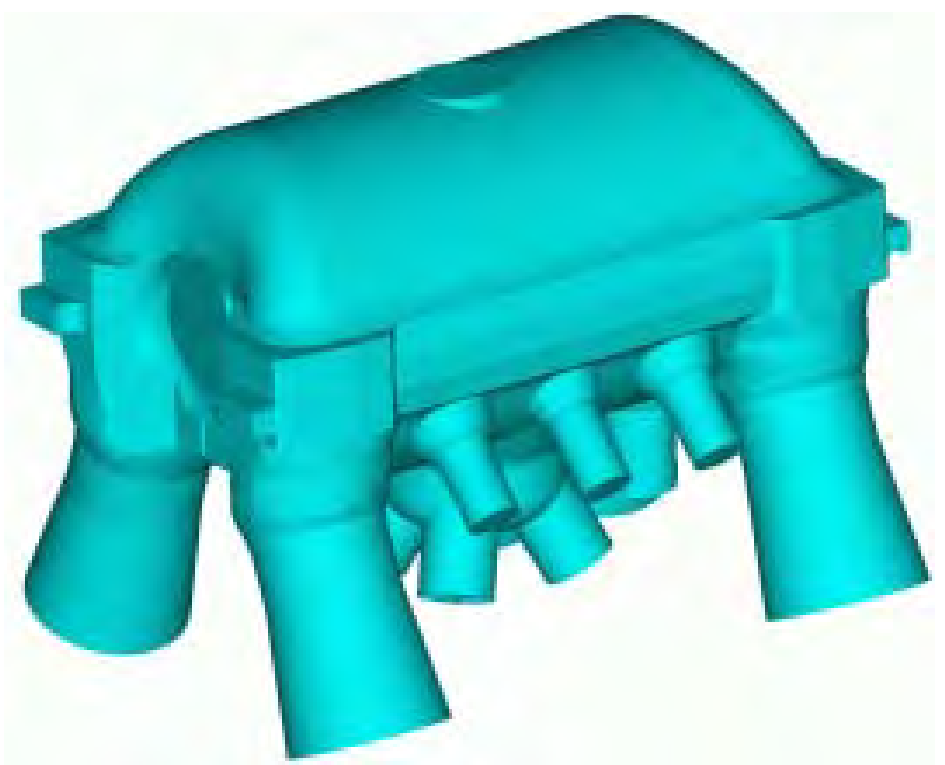

Fig. 5 Detailed Model of the Turbine High Pressure Part

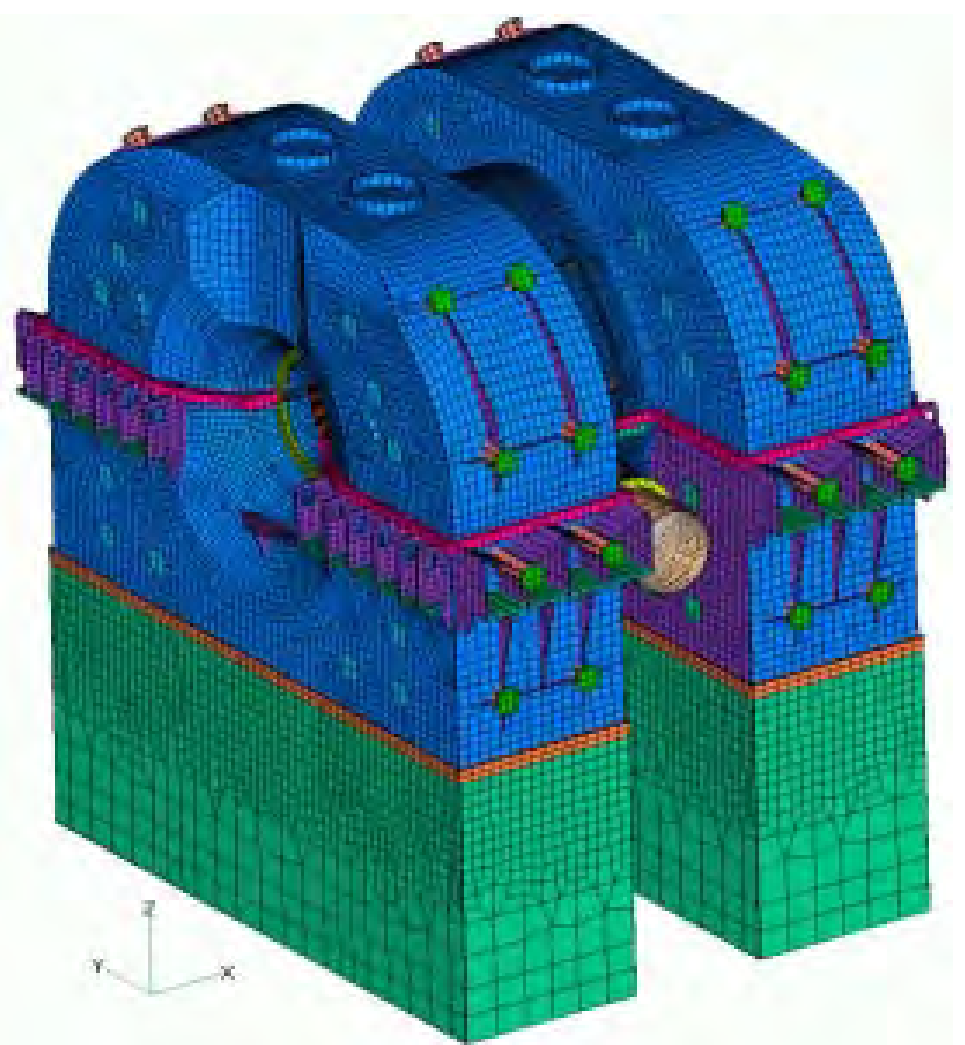

Fig. 7 Detailed Model of the Turbine Low Pressure Part

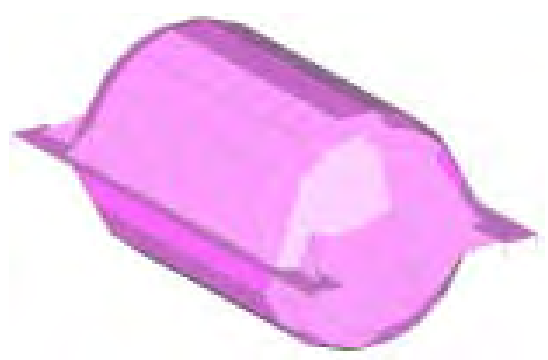

Fig. 6 Simplified Model of the Turbine High Pressure Part

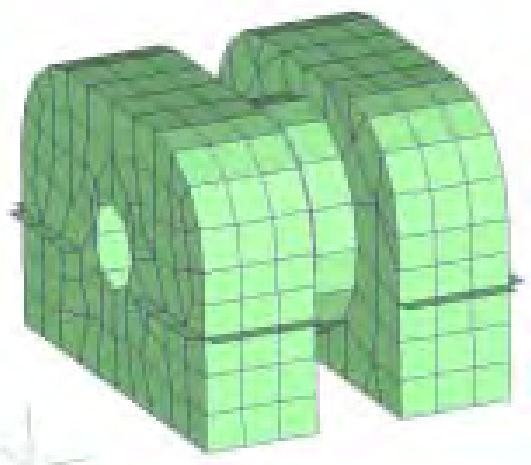

Fig. 8 Simplified Model of the Turbine Low Pressure Part

The high-pressure chamber of turbine is a massive steel casting device with the high pressure inside. It has approximately symmetrical structure about two planes. The first one is vertical and goes through the axis of turbine rotor. The second one is normal to the axis of turbine rotor. The high-pressure chamber has sixteen nozzles. Four inlet nozzles supply the device with high-pressure dry steam. The other twelve nozzles are for separation and outlet of steam.

With the help of CAD-CAE technique detailed model of this device was developed. It generally used finite elements of SOLID type. The simplified model was also created in accordance with the detailed one.

The considered turbine has three identical low-pressure chambers supported on the foundation slabs. Each low-pressure chamber is weld construction made of sheet steel with massive flanges and diaphragms with blades. 
It has middle part with double walls and outlet parts. The pressure of the steam going through the chamber drops from overpressure up to practically a total vacuum. It also has almost symmetrical structure about two planes: normal to the axis of turbine and vertical through that axis. The low-pressure chamber has two inlet and four outlet nozzles. There a few pressure stages provided with rotor and diaphragms' blades.

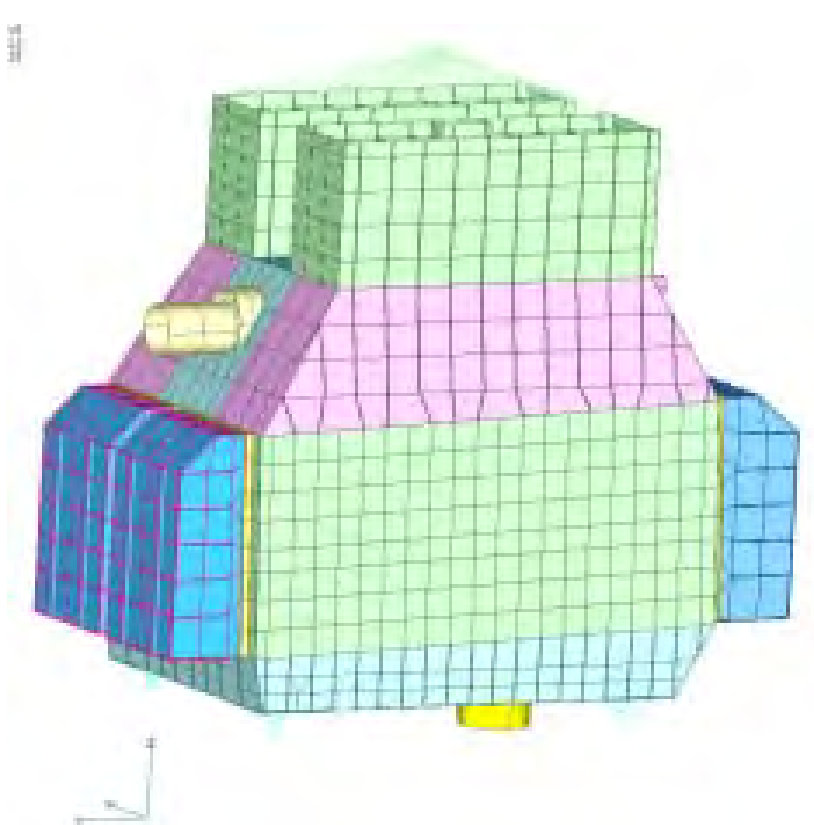

Fig. 9 Detailed Model of the Condenser

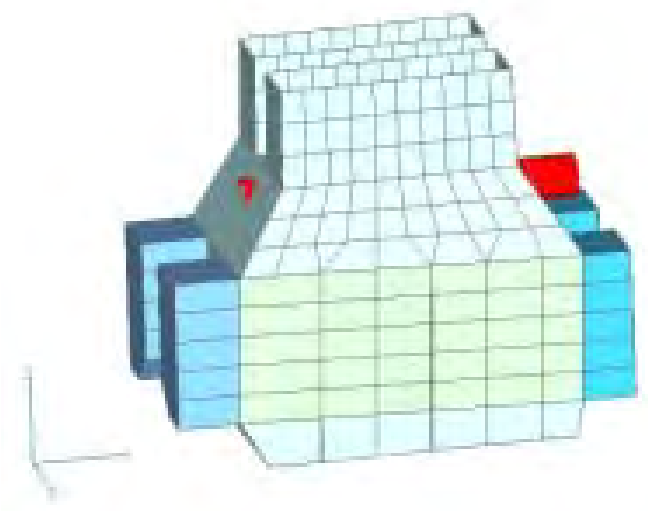

Detailed model of the low-pressure chamber was created generally with the help of SHELL elements. It has eigenvalues of 9.45 and $14.17 \mathrm{~Hz}$ corresponded to the two main mode shapes. Using that model, the simplified one was also made with the eigenvalues close to the frequencies found above $(9.40$ and $15.35 \mathrm{~Hz})$.

Three identical condensers also are the parts of the turbine. Each of them is based on the four spring supports. Upper flanges of connection nozzle of the condensers are welded to outlet nozzles of corresponding low-pressure chamber. There is a spatial frame inside condenser to support it against outer atmospheric pressure and the inner vacuum.

Detailed model of condenser was made generally of SHELL and BEAM elements and had eigenvalues 3.43 and $4.47 \mathrm{~Hz}$ for the main mode shapes. Appropriate simplified model had frequencies 3.54 and $4.36 \mathrm{~Hz}$ for the same modes. The evaluation of these eigenvalues was fulfilled with the models based on the spring supports and constrained on the edges of connection nozzles.

The turbine rotor lies on the 11 journal-bearings placed in the supports' cases on the cross fundament beams outside of high-pressure and low-pressure chambers. Stiffness of the rotor was modeled with the help of BEAM elements with suitable cross-sections (Fig.11). At the same time elastic modulus varies from section to section depending on temperature. Mass and inertia of the rotor and coupled features were described using concentrated masses and inertial elements (MASS elements).

Fig. 10 Simplified Model of the Condenser

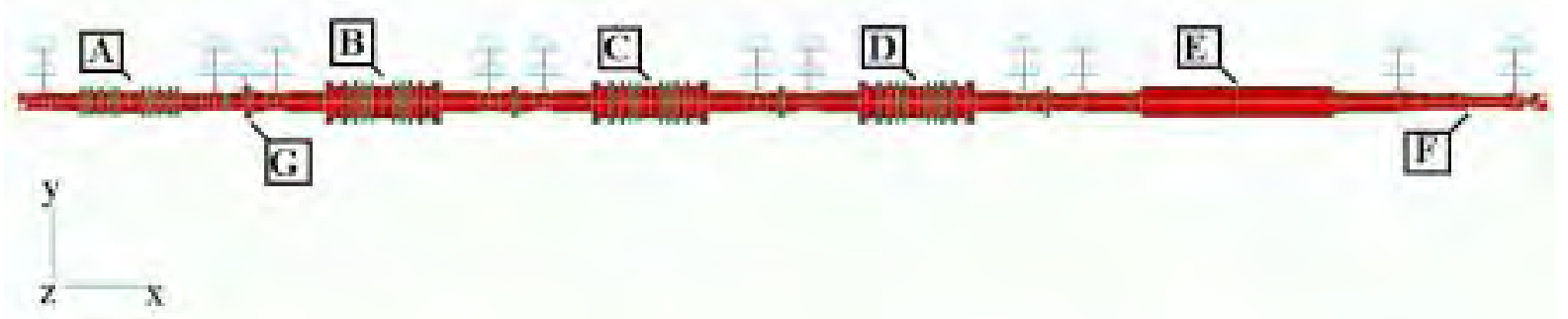

Fig. 11 Model of the Rotor (A-High Pressure Part, B, C, D-Low Pressure Part, $E$ - Generator Rotor, F-Exciter Rotor, $G$ - Thrust Bearing) 
To avoid the longitudinal oscillations the rotor is supported by thrust bearing which is the most loaded part of this subsystem. Moreover, this bearing has essentially non-linear stiffness under static as well as under dynamic load (fig. 12).

The supports' cases and coupled mass of underlying pedestal beams were modeled with SHELL elements. These supports were connected to the rotor with the non-linear SPRING elements which have stiffness of oil layer of the bearings.

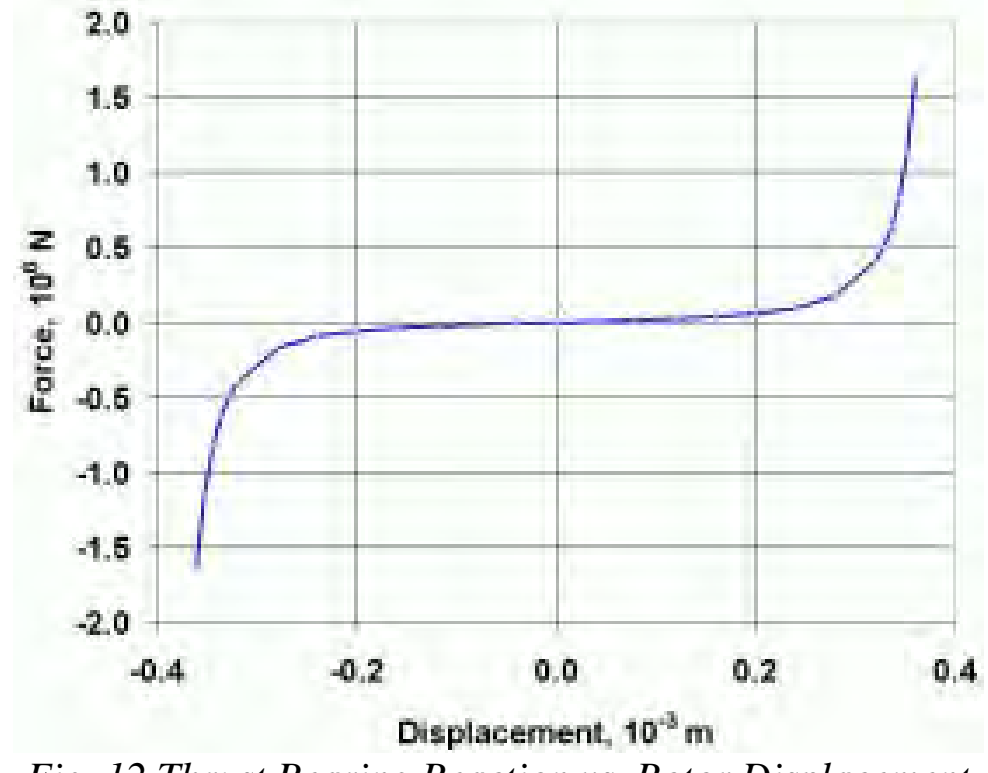

Fig. 12 Thrust Bearing Reaction vs. Rotor Displacement
The vibroisolation pedestal includes a massive reinforced concrete frame and vibroisolation system with elastic and viscous-elastic members of GERB GmbH (Germany). The vibroisolation is placed between horizontal concrete beams of buildings and the frame of the pedestal.

The model of vibroisolation pedestal includes BEAM and SHELL elements to describe the frame and SPRING elements with concentrated damping for vibroisolation. Namely viscous-elastic members were modeled by two parallel Maxwell's series of elastic spring and ideal viscous damper (Kostarev, 1994).

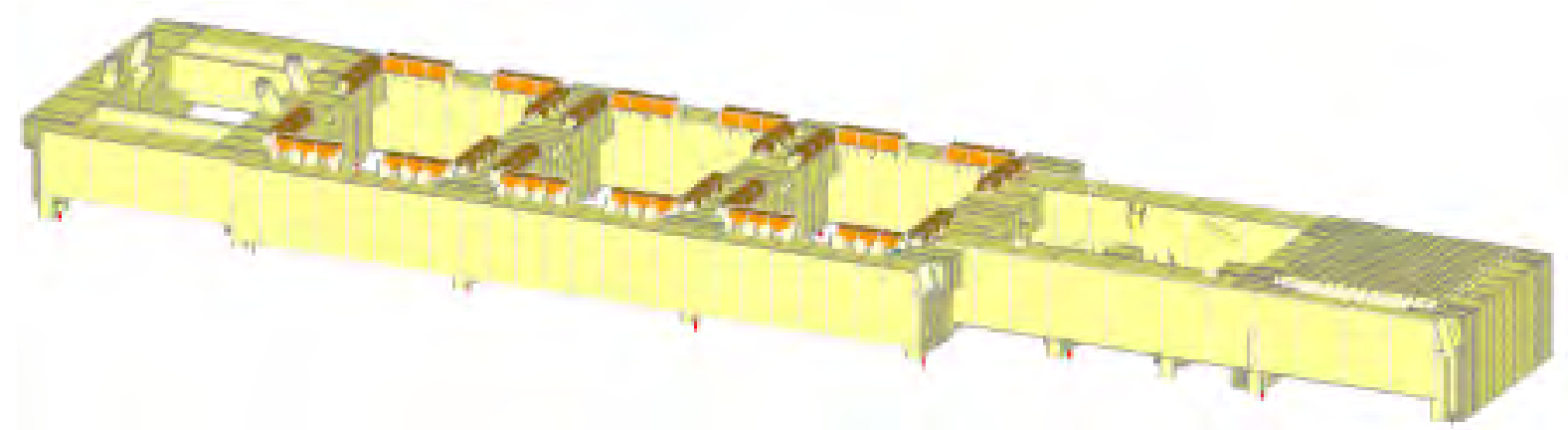

Fig. 13 Model of Vibroisolation Pedestal

To consider dynamic properties the eigenvalues and mode shapes were determined for the coupled "Vibroisolation Pedestal - Turbine" system. The linearized stiffness of thrust bearing were used for it. It should be noted that there are bending mode shapes excited in the case of non-uniform distribution mass, stiffness or damping in that system along the rotor axis (Fig. 14). Therefore, it may lead to rising of seismic inertial loads to the support system of the low pressure chambers. Moreover, the same effect can be caused by non-uniform stiffness of the underlying building beams which are the base of vibroisolation pedestal. 


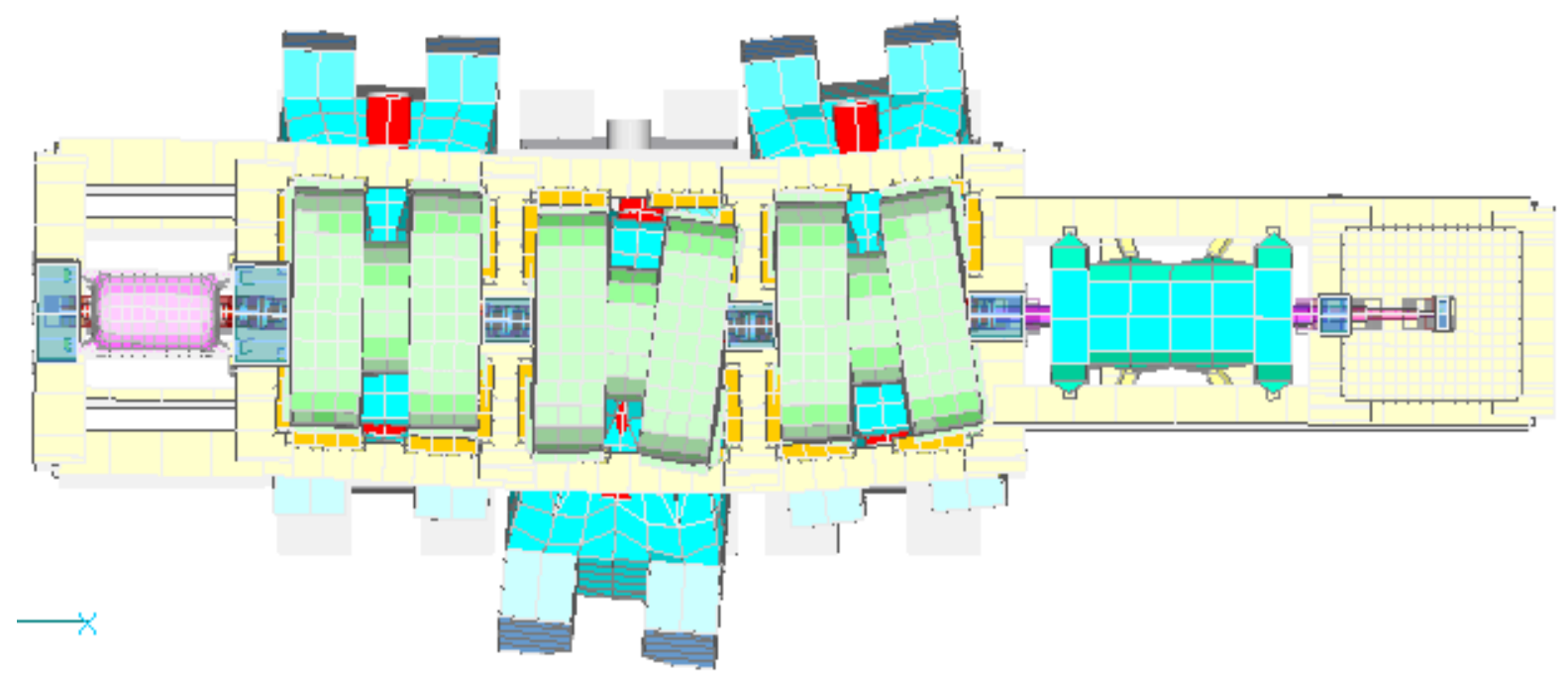

Fig. 14 «Vibroisolation Pedestal - Turbine» System. Mode Shape № 10 (3.18 Hz)

\section{DETERMINATION OF PIPELINES SEISMIC LOADS}

The main steam pipelines connected to the turbine are symmetrical positioned about vertical plane crossed through the rotor axis. A symmetrical half the model of pipelines is shown in Fig. 15.

The analysis of these pipelines subjected to the operational and seismic loads was performed. The response spectra method including multi-supports excitation was applied for seismic qualifica-tion of that system. The software dPipe developed by CKTI-Vibroseism was used for determination of deformation and stresses, temperature and seismic displacements of the pipelines' compensators, operational and seismic loads to the turbine nozzles.

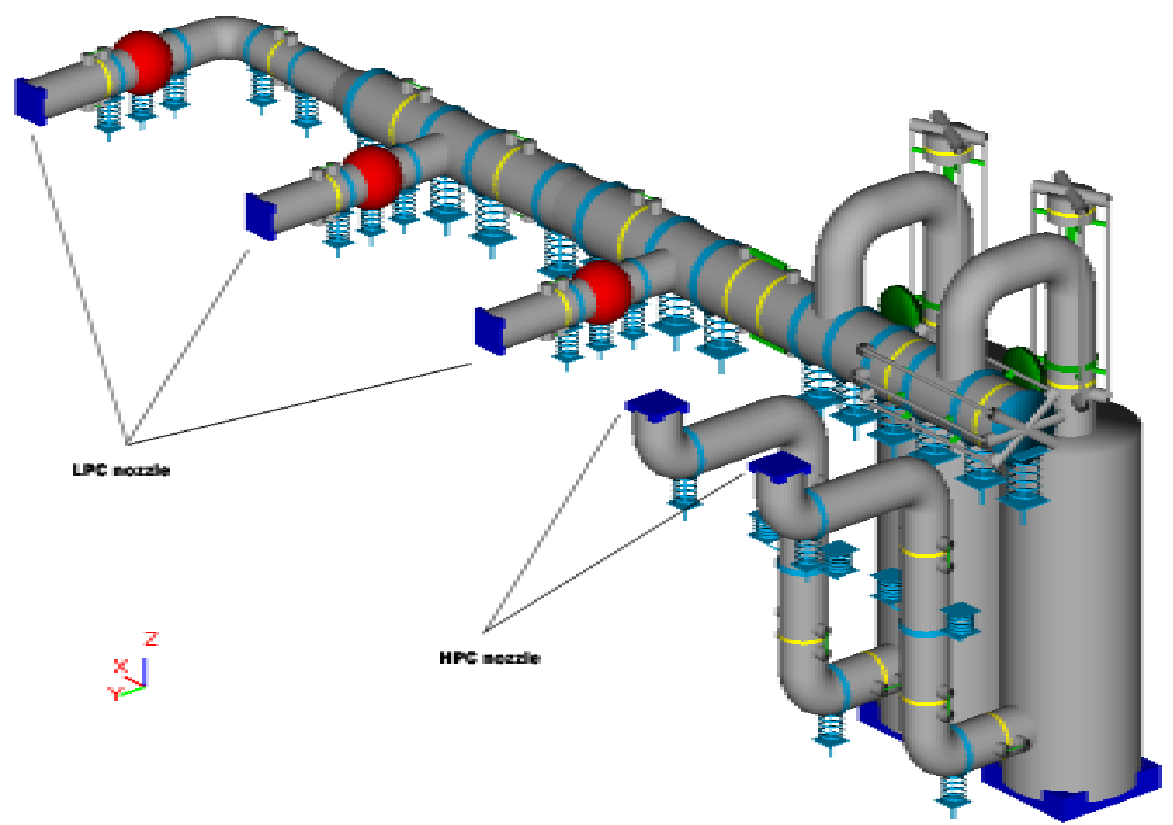

Fig. 15 Main Steam Pipelines Connected to Turbine

\section{THE SEISMIC ANALYSIS OF THE BVT SYSTEM}

The preliminary modal analysis of the whole BVT system determined eigenvalues and mode shapes under assumption of linear stiffness of the thrust bearing (Fig. 16-18). The modes responsible of oscillation of "vibroisolation pedestal - turbine" system itself were separated. The eigenvalues of these modes were significantly lower of the values observed for that system above. It proves that the stiffness of vibroisolation system and 
pedestal is comparable to the stiffness of underlying building supports. Therefore, the complex approach with the consideration of BVT system is absolutely suitable and justified.

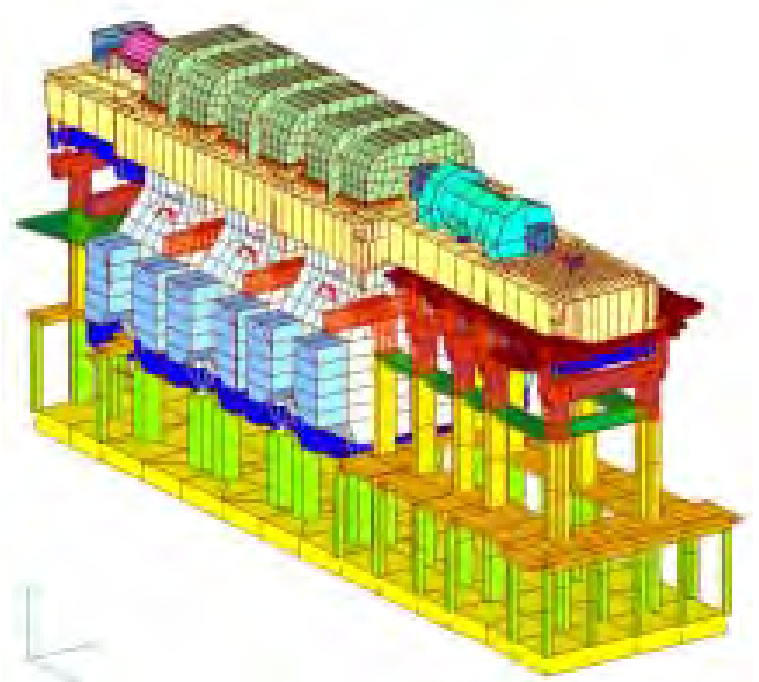

Fig. 16 Mode Shape № 1 of BVT System $(1.30 \mathrm{~Hz})$

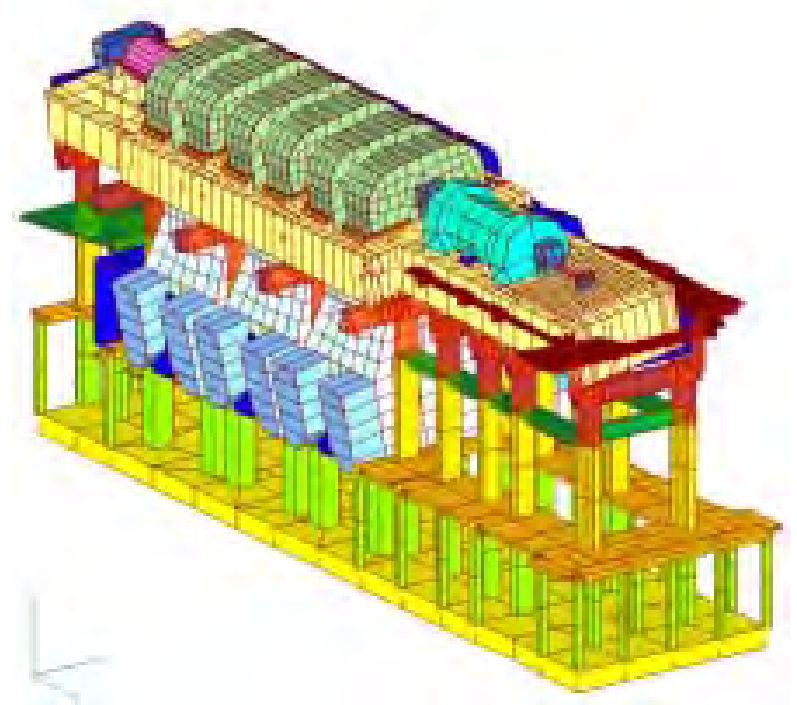

Fig. 17 Mode Shape № 2 of BVT System $(1.67 \mathrm{~Hz})$

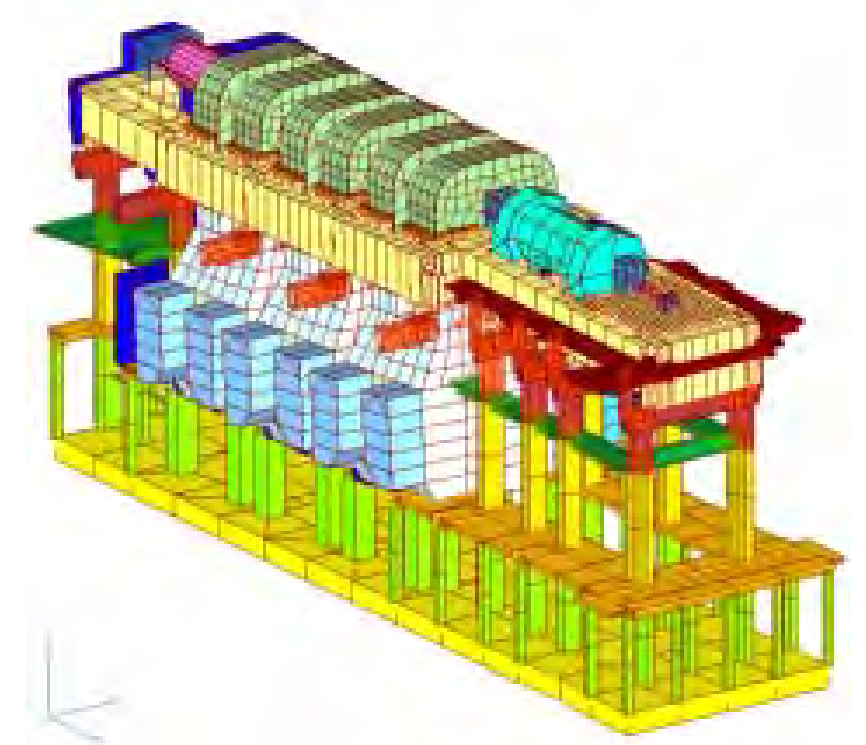

Fig. 18 Mode Shape № 3 of BVT System $(2.38 \mathrm{~Hz})$

Direct integration of the whole BVT system was carried out taking into account non-linearity of thrust bearing. The system was subjected to the excitation of time history three components acceleration on the base mat slab. Rayleigh damping was used for the structural elements of building and equipment. The concentrated damping was applied to model the viscous elements of vibroisolation system.

The following results of the analysis were found:

1. All range of inertial and reaction loads on the parts of the turbine was calculated.

2. The stress and strain fields of vibroisolation pedestal were estimated.

3. The load condition of capacity of vibroisolation system was analyzed.

4. All range of relative displacements between the turbine rotor and fixed parts was determined.

The time history relative displacements of the rotor about the high-pressure chamber and about the low-pressure chamber are shown below (Fig. 19 - 22). The analysis of the maximal absolute values of these displacements leads to conclusions about capacity of the turbine under the earthquake. 


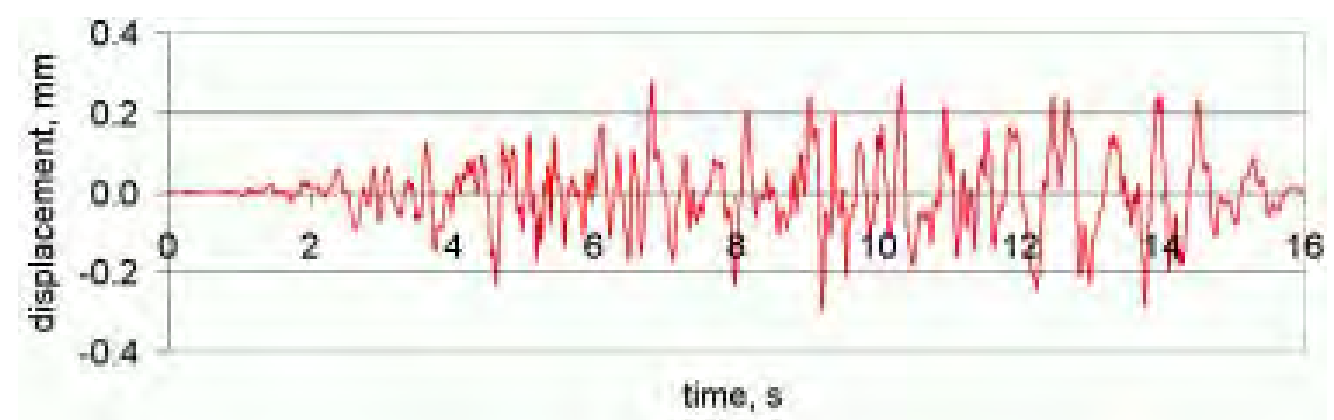

Fig. 19 Relative Rotor Displacement in High Pressure Part vs. Time. Axial Direction

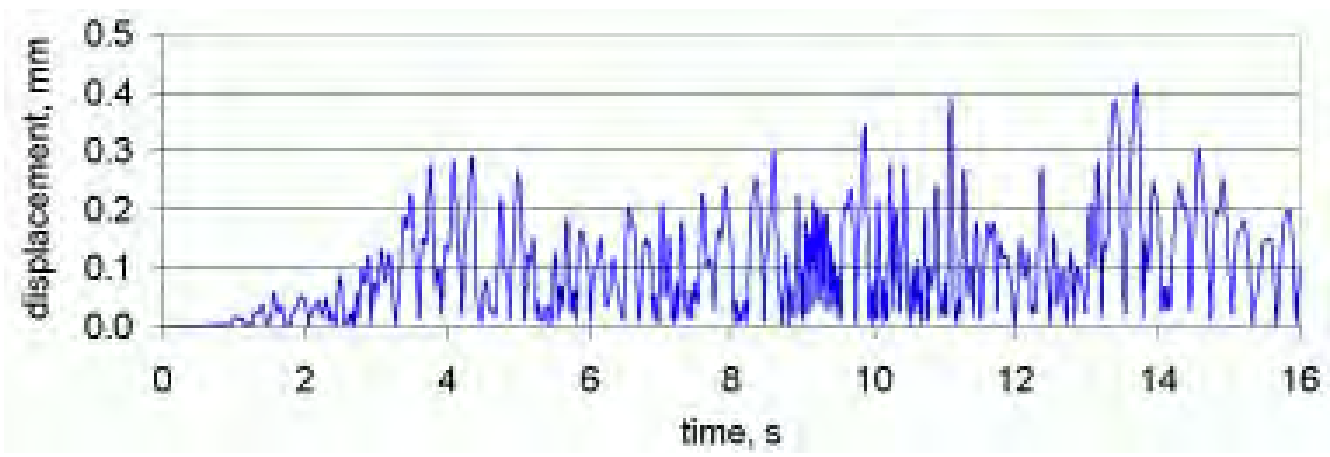

Fig. 20 Relative Rotor Displacement in High Pressure Part vs. Time. Radial Direction

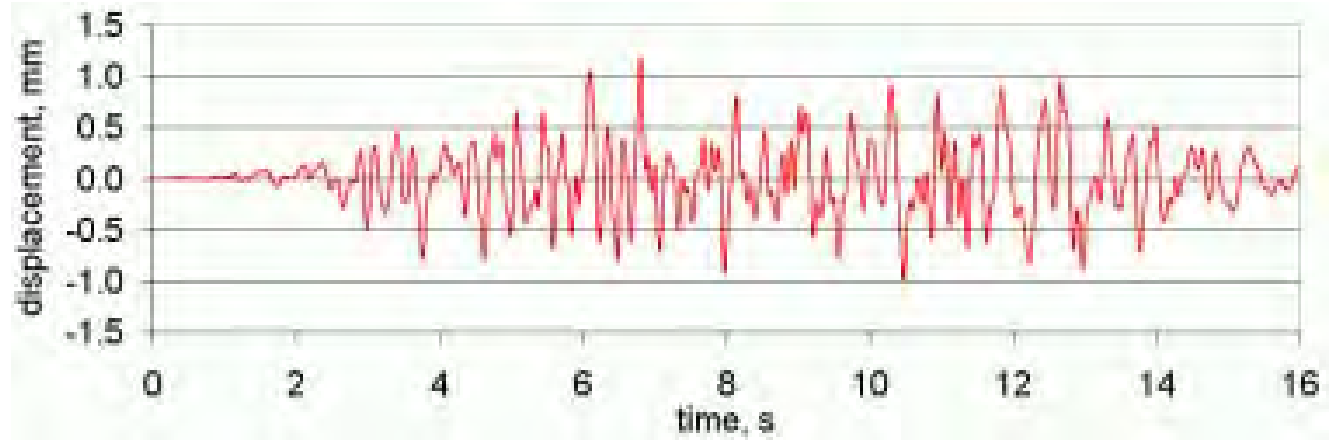

Fig. 21 Relative Rotor Displacement in Low Pressure Part vs. Time. Axial Direction

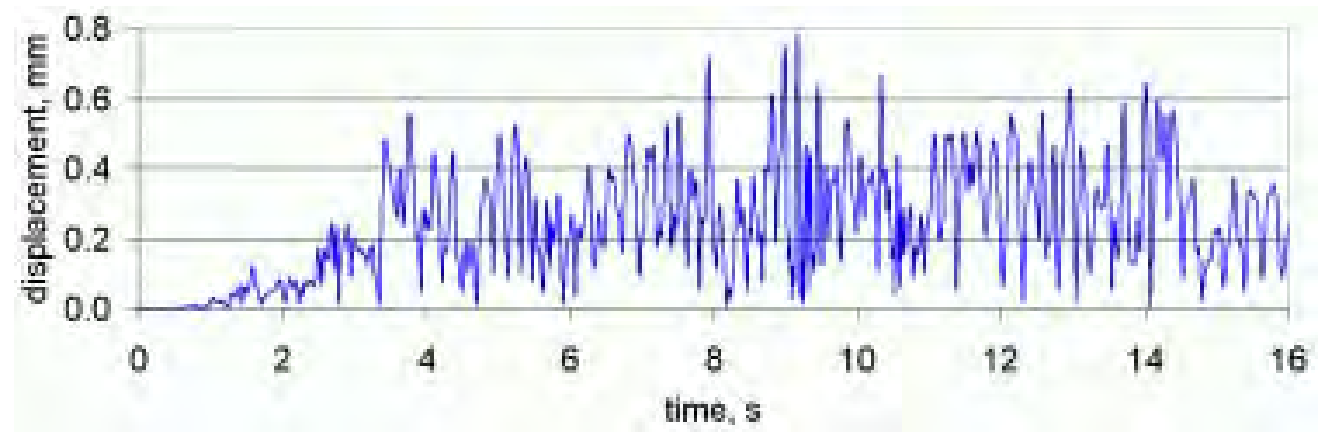

Fig. 22 Relative Rotor Displacement in Low Pressure Part vs. Time. Radial Direction

\section{ANALYSIS OF THE TURBINE PART USING DETAILED MODELS}

The loads obtained by seismic analysis of the whole BVT system were used in the analysis of each part of the turbine based on detailed three dimensional models. The results of the particular analysis of the high-pressure chamber, low-pressure chamber, condenser and the fragment of the support under seismic and operational loads are shown in Fig. 23-26. 
To perform such analysis three following steps were done:

1. Static analysis of the devices under operational loads (dead-load and pipelines load)

2. Series of the static analyses under maximal reactions of connected equipment and pipelines

3. Response spectra calculation to find deformation, stresses and reactions due to the inertial seismic loads

The results of these three steps were combined to evaluate summarized values.

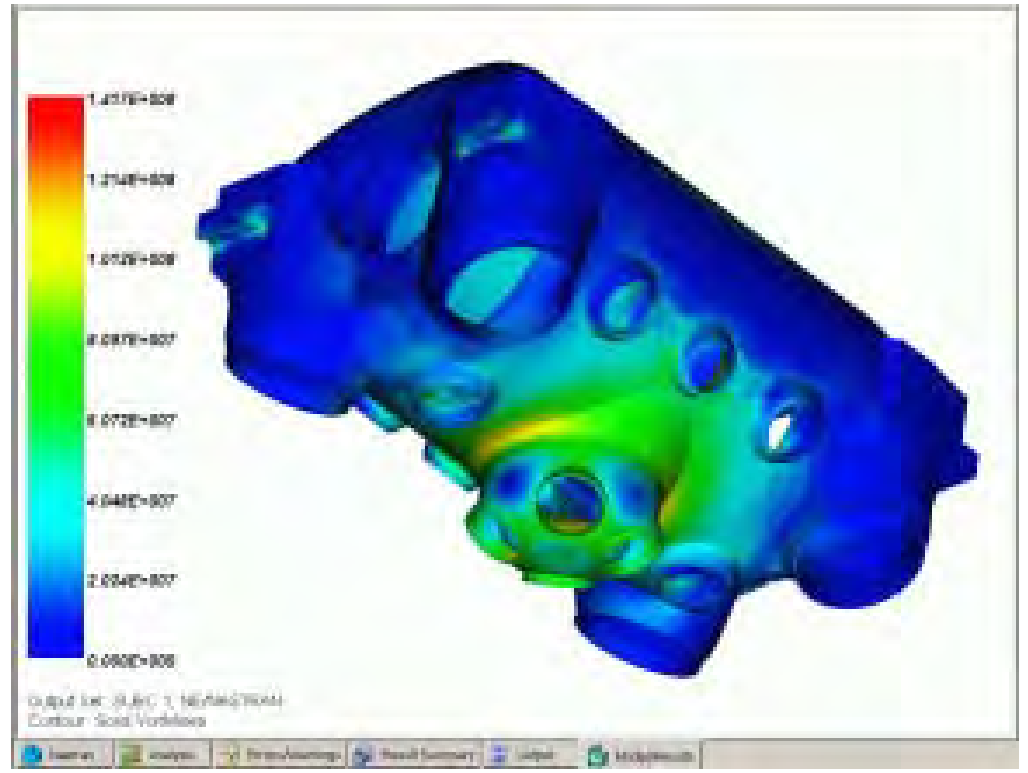

Fig .23 Effective Stresses for the High Pressure Chamber

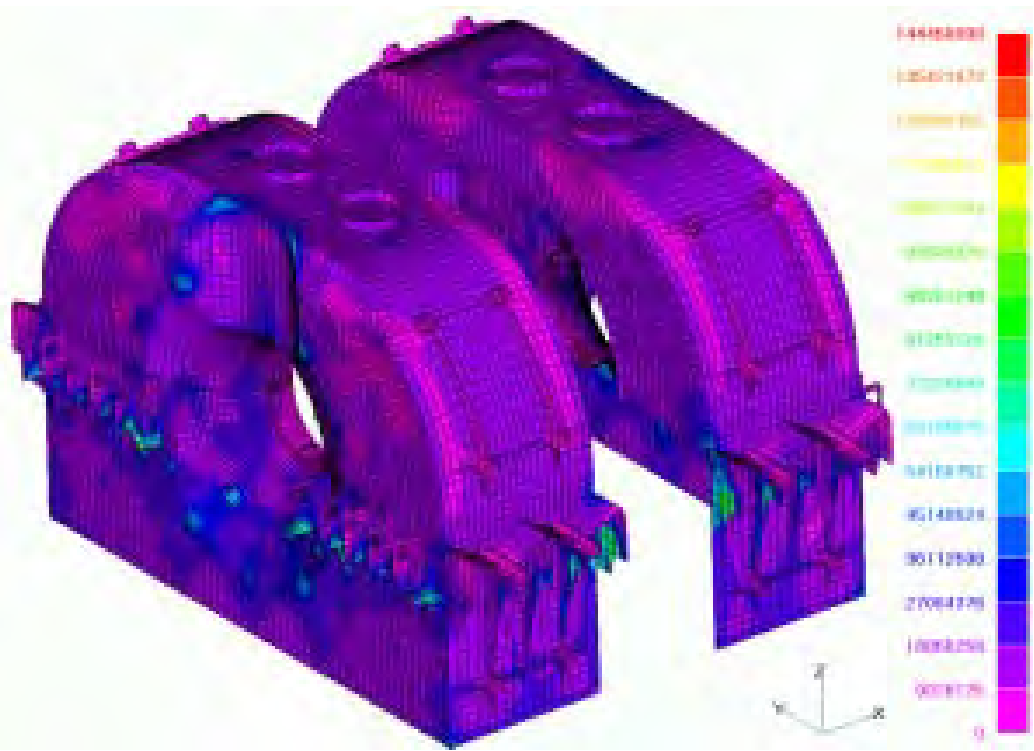

Fig .25 Effective Stresses for the Low Pressure Chamber

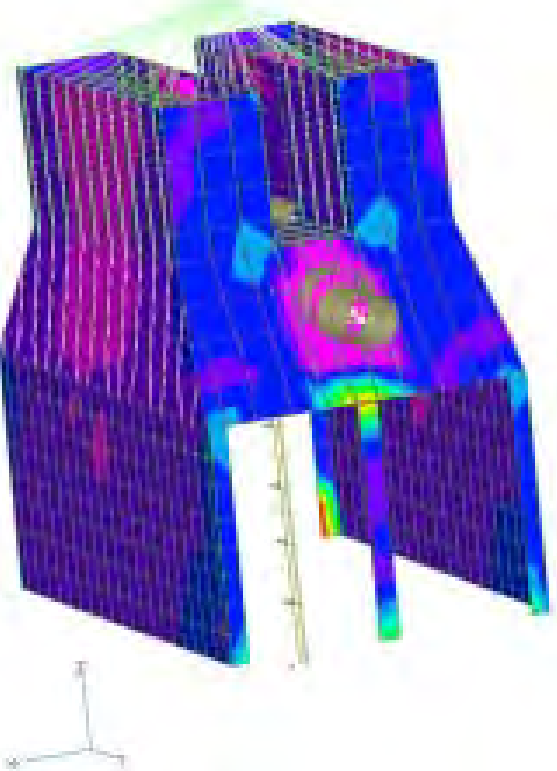

Fig .24 Effective Stresses for the Condenser

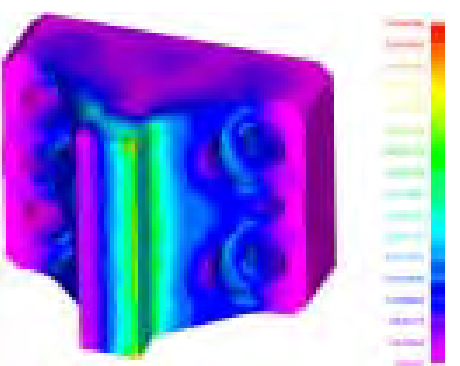

Fig .26 Effective Stresses for Support Element

\section{CONCLUSIONS}

The approach of seismic and other external events qualification of powerful NPP's turbines was developed. Under assumption of seismic excitation it was performed on the base of turbine hall's system for NPP being constructed at the present time. The analysis of coupled "Building - Vibroisolation Pedestal - Turbine" system proves the appropriateness of such approach and its efficiency. 


\section{REFERENCES}

GOSATOMNADZOR OF RUSSIA, (2002), NP-031-01, Norms for Seismic-Resistant Design of Nuclear Plants

IAEA, (1992), IAEA SAFETY SERIES No 50-SG-D15. Seismic Design and Qualification for Nuclear Power Plants. A Safety Guide, Vienna.

ASCE, (1998), ASCE 4-98 STANDARD. Seismic Analysis of Safety Related Nuclear Structures and Commentary, American Society of Civil Engineers.

Birbraer A.N., (1998), Seismic Analysis of Structures, Nauka, St-Petersburg.

US NRC, (1989), NUREG-0800, Standard Review Plan. Sections 3.7.1, 3.7.2. Seismic Design Parameters. Seismic System Analysis.

Kostarev V., Berkovski A., Kireev O., Vasilyev P., (1994), Application of mathematical model for high viscous damper to dynamic analysis of NPP. Proc. of 10th ECEE, Vienna. 